\title{
Migration Timing, Routes, and Connectivity of Eurasian Woodcock Wintering in Britain and Ireland
}

ANDREW N. HOODLESS, ${ }^{1}$ Game \& Wildlife Conservation Trust, Burgate Manor, Fordingbridge, Hampshire SP6 1 EF, UK

CHRISTOPHER J. HEWARD, Game \& Wildlife Conservation Trust, Burgate Manor, Fordingbridge, Hampshire SP6 1 EF, UK

\begin{abstract}
Migration represents a critical time in the annual cycle of Eurasian woodcock (Scolopax rusticola), with potential consequences for individual fitness and survival. In October-December, Eurasian woodcock migrate from breeding grounds in northern Eurasia over thousands of kilometres to western Europe, returning in March-May. The species is widely hunted in Europe, with 2.3-3.5 million individuals shot per year; hence, an understanding of the timing of migration and routes taken is an essential part of developing sustainable flyway management. Our aims were to determine the timing and migration routes of Eurasian woodcock wintering in Britain and Ireland, and to assess the degree of connectivity between breeding and wintering sites. We present data from 52 Eurasian woodcock fitted with satellite tags in late winter 2012-2016, which indicate that the timing of spring departure varied annually and was positively correlated with temperature, with a mean departure date of 26 March ( \pm 1.4 days SE). Spring migration distances averaged $2,851 \pm 165 \mathrm{~km}$ (SE), with individuals typically making 5 stopovers. The majority of our sample of tagged Eurasian woodcock migrated to breeding sites in northwestern Russia (54\%), with smaller proportions breeding in Denmark, Scandinavia, and Finland (29\%); Poland, Latvia, and Belarus (9.5\%); and central Russia (7.5\%). The accumulated migration routes of tagged individuals suggest a main flyway for Eurasian woodcock wintering in Britain and Ireland through Belgium, the Netherlands, and Germany, and then dividing to pass through the countries immediately north and south of the Baltic Sea. We found a weak positive relationship between breeding site longitude and wintering site latitude, suggesting broadly parallel migration routes from distinct breeding areas but some mixing of individuals from different breeding areas at the same wintering site.
\end{abstract}

Proceedings of the American Woodcock Symposium 11: 136-145

KEY WORDS: Argos PTT, banding, Europe, flyway, hunting, population management, satellite telemetry, site fidelity, spring temperature, stopover

An understanding of annual migrations is important for the conservation of many birds, especially for species that are hunted. There is increasing evidence that habitat quality and environmental conditions at wintering and breeding sites used by migratory species may profoundly influence the fitness and survival of individuals (Marra et al. 1998, Webster et al. 2002, Møller and Hobson 2003, Norris et al. 2003). For migratory birds that overwinter thousands of kilometers from their summer breeding grounds, any deterioration in quality or loss of suitable stopover sites and wintering areas is of conservation concern. For hunted species, such as the Eurasian woodcock (Scolopax rusticola), the cumulative level of harvest along the migratory route also affects survival rate and population viability. Evaluating the importance of pressures at stopover sites or wintering areas at the population scale requires detailed knowledge of migratory routes and linkages between breeding and wintering sites.

The European population of the Eurasian woodcock is estimated at 13.8-17.4 million birds, approximately $96 \%$ of which breed in Scandinavia, Finland, the Baltic states, and Russia (Birdlife International 2015). In winter (December-mid-March), the population is concentrated principally in Britain, Ireland, France, the Iberian Peninsula,

1 email: ahoodless@gwct.org.uk

https://doi.org/10.24926/AWS.0120 CC BY 4.0 
Italy, and Greece, with migrants starting to arrive from late September to mid-October (Gonçalves and Rodrigues 2017). The Eurasian woodcock is a prized quarry species in all of these countries in winter. It is also hunted in most central European countries during fall migration, and in Russia, Belarus, Romania, and Austria when males are roding (performing their courtship flights; Ferrand and Gossmann 2009a). Because of this widespread hunting, an understanding of migration routes, stopover sites, and timing is of conservation relevance for the species. Such knowledge is also important in evaluating the effects of changes in habitat and climate at stopover sites and wintering areas. To better inform management and hunting policies across Europe, reliable information is currently needed on the status of Eurasian woodcock in different countries and details of their migrations. Based on available information, which is of variable quality among countries, the European population of the Eurasian woodcock appears to be stable (Ferrand and Gossmann 2009a, Fokin and Blokhin 2013, Lindström et al. 2015), but the numbers breeding in Britain and Switzerland are believed to be declining (Estoppey 2001, Mulhauser 2001, Heward et al. 2015). There is some evidence from France and Spain that high shooting pressure is depressing adult survival in certain wintering regions (Tavecchia et al. 2002, Péron et al. 2011, Péron et al. 2012, Guzmán et al. 2017).

Until the last decade, knowledge of the movements of Eurasian woodcock has been based solely on recoveries of banded individuals. Band recoveries have been used to estimate the main breeding areas of Eurasian woodcock wintering in Britain, France, and Spain (Hoodless and Coulson 1994, Wernham et al. 2002, Bauthian et al. 2007, Guzmán et al. 2011). However, because the majority of recoveries are through hunting (e.g., $94 \%$ of all recoveries of known cause of Eurasian woodcock banded or recovered in Britain [Wernham et al. 2002]), analyses are subject to regional biases in recovery probability. With the exception of France, analyses have also been based on small numbers of recoveries $(<400)$ accumulated over approximately 100 years. They are subject to temporal biases in banding effort and in recovery probability, resulting from changes in hunting seasons. Recent studies employing stable hydrogen isotope analysis of feathers have provided a contemporary insight into the breeding origins of Eurasian woodcock wintering in Britain, France, and Spain at a meta-population scale, but they have still relied on band recoveries as priors in Bayesian assignment of isotope-ratio values (Van Wilgenburg and Hobson 2011; Hobson et al. 2013a,b; Hoodless et al. 2013).

Details of connections between particular breeding, stopover, and wintering sites and accurate timing of movements are still lacking for Eurasian woodcock and have proved extremely difficult to establish for most migratory birds on the basis of band recoveries. However, recent advances in tracking technologies and, in particular, the miniaturization of devices have enabled a rapid expansion in understanding of various aspects of bird migration. Geolocators, which log time-stamped daylight levels at regular intervals and enable crude determination of latitude and longitude at midday and midnight from sunrise and sunset times (Hill 1994), have been used to document complete migratory tracks for many bird species over long distances, including waders (e.g., Stutchbury et al. 2009, Egevang et al. 2010, Niles et al. 2010, Klaassen et al. 2011). For Eurasian woodcock, geolocators provide valuable data on the timing of migratory movements but are not sufficiently accurate for determining stopover locations (Hoodless et al. 2013). GPS tags have been increasingly deployed on larger birds in the last 5 years, yielding very accurate movement data (Guilford et al. 2008, Bouten et al. 2013), but until very recently have been too large and costly for deployment on Eurasian woodcock.

Satellite telemetry provides reasonably accurate locations and permits the tracking of animals in near realtime. A solar-powered 9.5-g PTT, suitable for use on birds $\geq 317 \mathrm{~g}$ based on the $3 \%$ of body mass rule, has been available since 2006, and 5.0-g and 3.0-g PTTs are now available. These have yielded crucial information on the

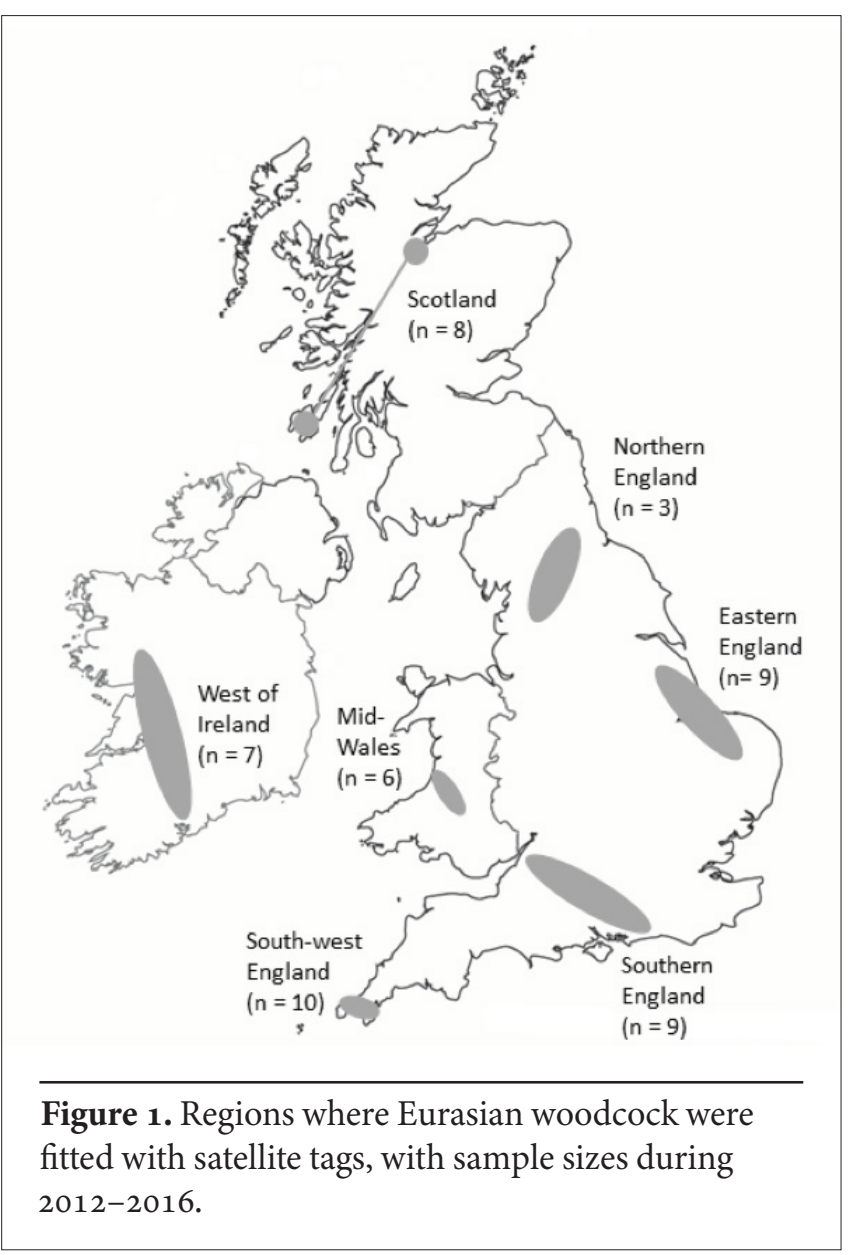


relationship between migration route and survival rate for declining species (e.g., Hewson et al. 2016). Tracking studies of Eurasian woodcock using satellite telemetry are currently underway in Britain, France, Spain, and Italy. Results from individuals tagged in late winter in northern Spain indicate a mean spring departure date of 20 March and breeding locations mainly in European Russia, along with the unexpected discovery of a breeding site in central Russia (Arizaga et al. 2014).

Our objectives were to determine migration timing, principal migration routes, and degree of connectivity between breeding and wintering grounds of Eurasian woodcock using wintering sites in Britain and Ireland. We discuss our findings in the context of working towards better flyway-level management of Eurasian woodcock in Europe.

\section{Study Area}

We worked in 7 geographically distinct regions in England $(n=4)$, Wales $(n=1)$, Scotland $(n=1)$, and Ireland $(n=1)$ to improve the likelihood of obtaining data representative of the range of migration routes used by Eurasian woodcock visiting Britain and Ireland (Fig. 1). We captured individuals at upland ( $>300 \mathrm{~m}$ asl, northern England, MidWales, Scotland) and lowland sites. Most of our study sites comprised grazed pastures and deciduous woodland, but in southern England there was a mixture of crop fields and pastures, and in eastern England mainly crop fields.

\section{Methods}

\section{SATELLITE TRACKING}

During late February - early March 2012-2016, we fitted 6o Eurasian woodcock with Argos satellite tags (9.5-g solar PTT, Microwave Telemetry, Inc., Columbia, MD). We captured individuals mainly on fields at night with a spot-lamp $(30 \mathrm{~W})$ and a landing net with a 3-m handle or during the day by walking through suitable patches of habitat to flush individuals into mist-nets across woodland rides. We aged Eurasian woodcock as first-year birds ( $<1$ year old) or adults ( $>1$ year old) on the basis of plumage (Ferrand and Gossmann 2009b). We mounted tags on the lower back using a Rappole-Tipton (1991) style legloop harness made from 1.6-mm diameter, UV-resistant, marine-grade rubber cord (EPDM cord, Polymax Ltd, UK) passed through biomedical silicone tubing (Silastic tubing, Cole Parmer, UK). The mean mass of individuals at tagging was $338 \pm 3 \mathrm{~g}$, such that the tag and harness (combined mass $11.1 \mathrm{~g}$ ) represented $3.29 \pm 0.03 \%$ of body mass. The fitting of satellite tags was licensed by the British Trust for Ornithology's Special Methods Technical Panel and approved by the Game and Wildlife Conservation Trust's Animal Welfare and Ethical Review Body.

The tag schedule alternated between a 10-hour 'on' period, during which the tag transmitted messages to Argos satellites, and a 48-hour 'off' period devoted to recharging the battery via the solar panel. We obtained PTT locations via the Argos system (Argos 2016), and all data were Kalman filtered before downloading (Lopez and Malardé 2011). The accuracy of position fixes delivered by satellite tags varied according to the number of satellite passes on which a tag was detected. Three or 4 passes resulted in accuracy of $150 \mathrm{~m}-1.5 \mathrm{~km}$ (location classes o-3), but fewer passes provided position estimates of unknown accuracy (location classes A and B). Our evaluation of datasets containing fixes of variable accuracy indicated that class A locations were often of comparable accuracy to class 1 locations (Hays et al. 2001). For Eurasian woodcock, class A and B locations have been estimated to be accurate to within $6 \mathrm{~km}$ and $10 \mathrm{~km}$, respectively (www.euskonews. com/o484zbk/gaia48404en.html). To make best use of our data, we initially included location classes $\mathrm{O}-3, \mathrm{~A}$, and $\mathrm{B}$ and plotted all locations on Google Earth (Google LLC, Mountain View, CA) to help identify and remove spurious locations. These were typically the first transmissions after the PTT had not transmitted for a period of more than a month, and mirror locations sometimes occurred after an individual had moved a long distance from its previous location.

\section{MIGRATION PARAMETERS}

We determined migration timing and stopover attributes using all transmissions for each individual until transmissions stopped. We classified all data rows according to the distance moved between consecutive locations, conservatively assuming no migration if the distance moved was $\leq 50 \mathrm{~km}$ but a migration flight if locations were $>50 \mathrm{~km}$ apart (Britten et al. 1999, Hewson et al. 2016). We defined stopovers as periods when locations from $\geq 2$ consecutive transmission periods fell within $50 \mathrm{~km}$ of each other. The minimum duration of stopovers we considered was 2 days. We estimated time of departure from the wintering site as the mid-point between the last location at the wintering site and the first location $\geq 50 \mathrm{~km}$ away. Similarly, we assumed time of arrival at the breeding site to be the midpoint between the last transmission at the final stopover location and the first transmission at the breeding site (always the maximum longitude and/or latitude reached before 1 June). Because locations were not received for every transmission cycle, we restricted departure and arrival time estimates to cases where the relevant consecutive transmissions occurred within 10 days. We defined duration of migration as the time between the estimated dates of spring departure from the wintering site and arrival at the breeding site. We processed data in the same way for fall migrations, with the exception that we calculated estimates of arrival time in Britain where relevant consecutive transmissions occurred within a 14-day period.

We calculated stopover locations as the median latitude and longitude of all locations within each period when 
individuals were considered not to be migrating. We calculated flight stage distances as the great-circle distance between stopover locations and migration distance as the sum of all stage distances. Migration speed was the total migration distance divided by the duration. We calculated flight speed according to the time and distance between consecutive locations where the distance moved exceeded $50 \mathrm{~km}$ and the time elapsed was at least 30 minutes. We used the mean values per stage flight per individual.

Calculation of the number of stopovers was complicated by the fact that sometimes, particularly in the second or subsequent springs when tag batteries had been depleted in winter, we received the first location for a month or more when an individual had commenced spring migration and had possibly already made $>1$ stage flight. In these cases, we estimated the number of stopovers as the number of known stopover locations plus 1, or occasionally 2, inferred stopovers based on information about the timing and speed of flights. Examination of data received during Argos transmission windows that spanned dawn and dusk indicated that migration flights were typically made at night, which in western Europe in late March - early April lasts 10-11 hours. Flight speed rarely exceeded $100 \mathrm{~km} / \mathrm{h}$; where a stage distance exceeded $1,000 \mathrm{~km}$, we thus added a stopover to the count and excluded the stage distance from the calculation of the mean. In fall, we used $1,200 \mathrm{~km}$ as the cutoff for the maximum stage flight distance.

\section{Data Analysis}

We based analyses of migration timing on Julian date and included data for all individuals in all years, including identity of each individual as a random factor to control for individual effects. We based other analyses and summary statistics on mean values per individual for those tracked in $>1$ year. We calculated statistics in Genstat v18.1. We present all mean values with standard deviations except where otherwise indicated.

We analysed variation in onset of spring migration using a generalized linear mixed model (GLMM) with departure date as the dependent variable, individual age and year as factors, latitude and longitude of the winter and breeding sites as covariates, and identity of an individual as a random factor. We specified a normal error term and an identity link function, and included the interactions age $\times$ year, winter site latitude $\times$ longitude, and breeding site latitude $\times$ longitude. We then examined the influence of temperature on departure date with a GLMM, with departure date as the dependent variable, individual age as a factor, and mean March temperature as a covariate, including the interaction temperature $\times$ individual age. We specified the random effect as region/individual identity/year because each region had $>1$ tagged individual, and years were repeated measures for some individu- als. We obtained annual mean March temperature values for all regions where we tagged Eurasian woodcock from the Met Office (www.metoffice.gov.uk/climate/uk/summaries/2013/march/regional-values) and MET éireann (http://archive.met.ie/climate-request/).

We examined duration of spring migration with a GLMM using normal errors and an identity link function. We specified individual age and year as factors, and included departure date and migration distance as covariates, and identity of individuals as a random factor. Owing to smaller sample sizes in fall, we restricted comparisons of total migration distance, number of stopovers, and flight stage distance between spring and fall to individuals tracked in both seasons within the same year and conducted paired $t$-tests.

We examined connectivity between breeding and wintering sites with linear regression of latitudes and longitudes, using the coordinates for each individual once, in the first year that they were tracked. We crudely compared similarity of fall to spring migration routes by measuring the perpendicular distance, in Google Earth, from fall stopover locations to the spring track $\leq 3$ points for each individual where complete or partial fall tracks were obtained. We averaged values per individual before calculating an overall mean.

\section{Results}

Seven tags did not deliver useful data because 4 individuals were resident breeders in Britain and 3 individuals were presumed predated prior to migration. We lost contact with 1 individual during its first spring migration, leaving 52 individuals that completed $\geq 1$ spring migration and 18 individuals for which we tracked multiple migrations.

\section{TIMING OF MIGRATION}

Peak spring departure of Eurasian woodcock from Britain and Ireland was during the third week of March, but departure times spanned a 5-week window from 3 March to 13 April (Table 1). Spring departure date varied among years and differed between age classes (GLMM year $F_{4,34.0}$ $=17.36, P<0.001$, bird age $F_{1,43.9}=4.24, P=0.046$ ), with winter and breeding site latitude and longitude, and model interactions, having no significant effects. The onset of migration was appreciably later in spring 2013, when mean temperature in Britain in March was $3.3^{\circ} \mathrm{C}$ below the 1981-2010 average (mean departure dates 21 March 2012, 9 April 2013, 22 March 2014, 24 March 2015, 26 March 2016). Adult Eurasian woodcock departed, on average, $4.5 \pm 2.2$ days $( \pm$ SE) before first-year individuals. Departure date was correlated with mean March temperature, explaining the variation among years (GLMM March temperature $F_{1,45.2}=56.79, P<0.001$, individual age $F_{1,48.8}$ $=6.12, P=0.017$, March temperature $\times$ individual age $F_{1,43.4}$ $=0.57, P=0.456)$. Eurasian woodcock commenced migra- 
tion $3.9 \pm 0.5$ days $\left( \pm\right.$ SE) earlier for every $1^{\circ} \mathrm{C}$ increase in March temperature.

Eurasian woodcock migration in spring consisted of a series of flights averaging $413 \pm 248 \mathrm{~km}$, with individuals typically making 5 stopovers before reaching their breeding sites. Spring migration was completed in an average of 6 nocturnal flights, with mean flight speed estimated at 70 $\pm 39 \mathrm{~km} / \mathrm{h}$. Peak arrival at breeding sites was in mid-April, with individuals taking an average of 23 days to complete migration (Table 1). Duration of spring migration was negatively related to departure date and positively related to total migration distance, such that migrations were reduced by $0.60 \pm 0.13$ day ( \pm SE) for every day that departure was delayed and increased by $0.69 \pm 0.13$ day $( \pm$ SE) for every extra $100 \mathrm{~km}$ travelled (GLMM departure date $F_{1,37.4}=21.70, P<0.001$, migration distance $F_{1,39.6}=30.25, P$ $<0.001$, individual age and year effects not significant).

Our data on fall migrations were relatively sparse, but indicated that Eurasian woodcock typically left their breeding sites around 10 October and arrived in Britain or Ireland on 10 November (Table 1). Total migration distance was $182 \pm 328 \mathrm{~km}$ shorter in fall than in spring (paired $t$-test $t_{20}=-2.55, P=0.019$ ). On average, Eurasian woodcock made 2 fewer stopovers on fall migration than in spring (paired $t$-test $t_{13}=-4.09, P=0.001$ ), and mean flight stage distance was $114 \pm 317 \mathrm{~km}$ greater in fall than in spring, although the difference was not statistically significant (paired $t$-test $t_{26}=1.87, P=0.073$ ). Sample sizes in fall were too small for comparison of the duration of spring and fall migrations.

\section{BREEDING LOCATIONS AND}

\section{MIGRATORY CONNECTIVITY}

Eurasian woodcock tagged in Britain and Ireland migrated to breeding sites in 8 countries: Denmark $(n=1,1.9 \%)$, Norway $(n=4,7.7 \%)$, Sweden $(n=7,13.5 \%)$, Finland $(n=$ $3,5.8 \%)$, Poland $(n=1,1.9 \%)$, Latvia $(n=3,5.8 \%)$, Belarus $(n=1,1.9 \%)$, and Russia $(n=32,61.6 \%)$. Of those breed- ing in Russia, 28 settled in northwestern Russia, 1 in Sverdlovsk province, just east of the Ural Mountains $\left(57^{\circ} 26^{\prime} \mathrm{N}\right.$, $59^{\circ} 51^{\prime} \mathrm{E}$ ), and 3 used sites in Krasnoyarsk province, central Russia (mean $59^{\circ} 28^{\prime} \mathrm{N}, 91^{\circ} 52^{\prime} \mathrm{E}$ ). Three of the individuals breeding in Norway were tagged in Scotland, with the fourth tagged in Ireland. The 3 that migrated to central Russia were tagged in southwestern England $(n=2)$ and eastern England $(n=1)$. Mean migration distance was 2,851 $\pm 1,168 \mathrm{~km}$, but the 3 individuals breeding in central Russia undertook migrations of $6,274 \pm 288 \mathrm{~km}$ and arrived on 10 May \pm 12.1 days.

We found a weak relationship between breeding site longitude and winter latitude $\left(r_{52}=-0.314, P=0.023\right)$, which remained significant with the exclusion of the 3 individuals that bred in central Russia $\left(r_{49}=-0.284, P=\right.$ o.048). We found no relationships between breeding site longitude and winter longitude $\left(r_{52}=0.060, P=0.673\right)$ nor between breeding site latitude and winter latitude $\left(r_{52}=\right.$ $0.004, P=0.975)$ or winter longitude $\left(r_{52}=0.135, P=0.341\right)$ for individuals wintering in Britain and Ireland. However, individuals tracked in multiple years were largely faithful to the same breeding and wintering sites. Of 43 winter locations, relating to 30 individuals, in winters following the season of tagging, 39 (91\%) were the same as the original tagging location. Three individuals changed winter site ( 1 of them twice). Two individuals were tagged in the relatively cold spring of 2013 , and all 3 subsequently used winter sites to the east of where they were tagged. Of 28 breeding locations relating to 18 individuals, 27 (96\%) were the same as those used in the first summer. The individual that changed breeding sites flew to northwestern Russia in 2015 and southwestern Sweden in 2016.

\section{MIGRATION ROUTES}

With the exception of individuals breeding in Norway, most minimized the distance flown across the North Sea on spring migration by passing through France, Belgium, or the Netherlands, and then Germany, before crossing

Table 1. Timing, duration, and distance of spring and fall migrations of Eurasian woodcock tracked by satellite telemetry in western Europe during 2012-2016.

\begin{tabular}{|c|c|c|c|c|c|c|}
\hline \multirow[b]{2}{*}{ Parameter } & \multicolumn{3}{|c|}{ Spring migration } & \multicolumn{3}{|c|}{ Fall migration } \\
\hline & $n$ & Mean \pm SD & Range & $n$ & Mean \pm SD & Range \\
\hline Onset of migration & 52 & $26 \mathrm{Mar} \pm 10.3 \mathrm{~d}$ & 3 Mar-13 Apr & 13 & $10 \mathrm{Oct} \pm 32.3 \mathrm{~d}$ & $13 \mathrm{Jul}-18 \mathrm{Nov}$ \\
\hline Arrival at breeding/winter site & 65 & $19 \mathrm{Apr} \pm 13.7 \mathrm{~d}$ & 21 Mar-25 May & 4 & $10 \mathrm{Nov} \pm 10.6 \mathrm{~d}$ & $3-23$ Nov \\
\hline Duration of migration (days) & 46 & $23.3 \pm 13.2$ & $3-50$ & 4 & $19.5 \pm 7.4$ & $10-27$ \\
\hline Total migration distance $(\mathrm{km})$ & 50 & $2,851 \pm 1,168$ & $988-6,605$ & 18 & $3,018 \pm 1360$ & $1,287-6,365$ \\
\hline Number of stopovers & 73 & $4.7 \pm 2.7$ & $0-14$ & 14 & $3.4 \pm 2.1$ & $1-9$ \\
\hline Flight stage distance $(\mathrm{km})$ & 337 & $413 \pm 248$ & $53-992$ & 55 & $515 \pm 306$ & $84-1,109$ \\
\hline
\end{tabular}


Denmark and north of the Baltic Sea to reach Sweden or Finland or heading south of the Baltic Sea to reach Finland, Belarus, or northwestern Russia (Fig. 2). Consequently, Germany, Poland, Lithuania, Latvia, and Belarus constitute an important spring migration corridor supporting a large proportion of the stopovers by migrant Eurasian woodcock wintering in Britain and Ireland (Fig. 3). Migration routes of individuals tracked in fall were largely similar to those taken in spring, with a mean divergence between routes of $124 \pm 59 \mathrm{~km}$.

\section{Discussion}

Timing of migration in many species of birds has been shown to be dependent on weather, especially temperature (Sokolov 2001, Marra et al. 2005). It is not surprising that the timing of spring migration in Eurasian woodcock varied annually and was related to March temperature, given the species' dependence on soil invertebrates, particularly earthworms, and the influence of temperature on the accessibility of this food. Birds that undertake migration as a series of long flights, and typically most waders, need to store sufficient energy as fat before departure. Rates of food intake and energy storage in Eurasian woodcock are poorly understood, but when conditions are relatively cool in spring, it is likely to take individuals longer to attain their minimum departure mass, owing to increased thermoregulatory demand and reduced accessibility of food. By departing too soon, Eurasian woodcock also risk encountering frozen ground, or at least difficult feeding conditions, on the migration route when they have already exhausted a large proportion of their energy reserves, the consequences of which have been documented in other species (Whitmore et al. 1977, Marcström and Mascher 1979, Tryjanowski et al. 2004).

The fact that adult Eurasian woodcock set off on spring migration earlier than first-year individuals might be related to adults being better able to judge the appropriate time, based on experience. The earlier departure gives adults the advantage of reaching the breeding grounds first and potentially occupying the best habitat or, in the case of males, mating with a female before first-year males arrive. There is good evidence within migratory passerines that the males that arrive earliest on the breeding grounds typically occupy the best territories and have the highest reproductive success (Aebischer et al. 1996, Lozano et al. 1996, Kokko 1999, Currie et al. 2000). Competition for early arrival tends to be most intense in species with polygynous mating systems (Hasselquist 1998). Our data indicate that Eurasian woodcock have the capacity to partially compensate for a late spring departure by reducing the overall duration of their migrations, suggesting that in typical years they do not fully exhaust their energy reserves before each stopover.

The Argos PTTs yielded relatively poor data on fall migration, owing to reduced efficiency of solar charging between August and March. The complete datasets obtained for fall migrations suggest that migration is completed more quickly in fall than in spring, which is plausible if individuals wait on the breeding grounds until the onset of freezing weather and then need to keep moving ahead of it. However, a larger dataset is required to confirm that this is the case. Archival GPS loggers could provide more reliable data on fall migration, as current small models are capable of collecting accurate data for up to a year without the need for solar charging. GPS-GSM tags are also likely to be small enough for deployment on Eurasian woodcock within the next 1-2 years.

Our sample of tracked Eurasian woodcock indicates that northwestern Russia is a key breeding area for individuals wintering in the British Isles, with a major flyway for these individuals running through the countries immediately south of the Baltic Sea to Finland and northwestern Russia, along with a route through Denmark and southern Sweden up into Sweden and across to Finland. More accurately quantifying the relative contributions of these breeding areas to the British and Irish wintering Eurasian woodcock population, and the relative importance of the different flyways, will require further information. Specifically, data are needed on mid-winter densities of Eurasian woodcock in the regions where individuals were tagged, the number of individuals tagged at each location needs to be taken into account, and, ideally, a larger sample of individuals should be tracked to confirm the findings to date

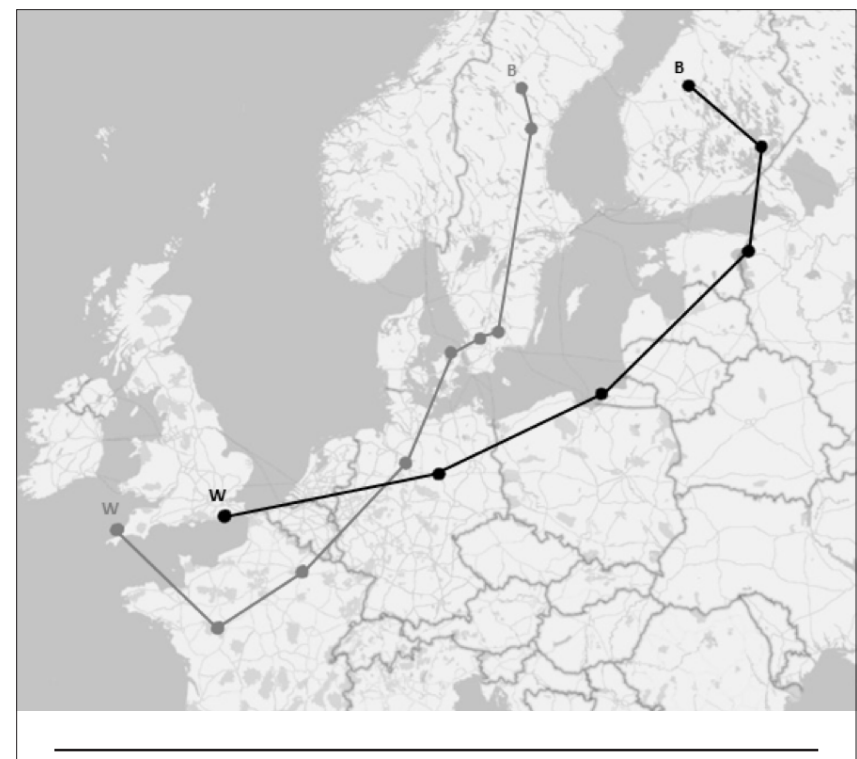

Figure 2. Examples of spring migration journeys by Eurasian woodcock from winter sites (W) in southern England to breeding sites (B) in central Sweden and southern Finland, illustrating the avoidance of long sea crossings. Dots indicate stopover locations. 
and fill gaps for migration routes that we may not have detected with our small sample of tagged individuals.

Eurasian woodcock breeding in Norway flew directly across the North Sea. This is the shortest route, but it can be more perilous than migrating over land. Fishermen have reported hundreds of Eurasian woodcock drowned in the North Sea following storms, and they have been recorded settling on oil rigs (McKelvie 1990:94, m.facebook.com/story.php?story_fbid $=2151841638159652$ \&id=177523075591528). One of the individuals we tagged in Scotland and which spent the summer in Norway was caught in a storm on its fall migration in October 2012, turned back, and failed to make it to the Norwegian coast. Our data indicated that the majority of Eurasian woodcock breeding in other countries followed routes that largely avoided sea crossings.

The 3 individuals that travelled to breeding sites in central Russia flew approximately twice as far east as the furthest banded Eurasian woodcock recovered in Russia. One of 12 individuals fitted with satellite tags in Spain during 2006-2013 and completing journeys to their breeding sites travelled to a very similar area (Arizaga et al. 2014), as did one of 24 birds tagged in France in 2015-2016 (www. becassesmigration.fr/). This was previously unrecognized as a breeding area for Eurasian woodcock wintering in western Europe and, owing to the low density of human habitation, is unlikely to have ever been detected through band recoveries.

We found no evidence of high connectivity between particular breeding areas and wintering areas in Eurasian woodcock. The weak correlation between breeding longi- tude and winter latitude indicates broadly parallel directions of departure from the breeding grounds but considerable mixing of individuals from quite separate breeding sites at the same wintering site. This pattern could be better confirmed by pooling data from Eurasian woodcock tagged at winter sites in several countries and re-examining the relationship. Eurasian woodcock tagged in Spain typically bred further east than the individuals tagged in our study: of 12 that reached breeding sites, 1 settled in Finland, 3 in northwestern Russia, 6 were between Moscow and the Ural Mountains, 1 was near the Ukraine-Russia border, and 1 was in central Russia (Arizaga et al. 2014). It seems likely that first-winter Eurasian woodcock leave the breeding grounds in a roughly southwesterly direction in their first fall, and that the site at which they end up spending the winter is to some extent determined by the weather encountered during their first migration. In subsequent years, having found a suitable site at which they were able to survive the winter, they then appear faithful to the same wintering site, unless displaced by spells of cold weather, as suggested by Wilson (1983). High winter-site fidelity has been documented in most of the species within the family Scolopacidae in which it has been examined (Smith et al. 1992, Burton and Evans 1997, Burton 2000, Lourenço et al. 2016).

Satellite tags have now been deployed in 4 distinct wintering areas for Eurasian woodcock in Europe, and have significantly advanced our understanding of the species' spring migration strategy, migration routes, and breeding areas. The smaller models, however, as deployed on Eurasian woodcock, rely on solar charging of the battery and

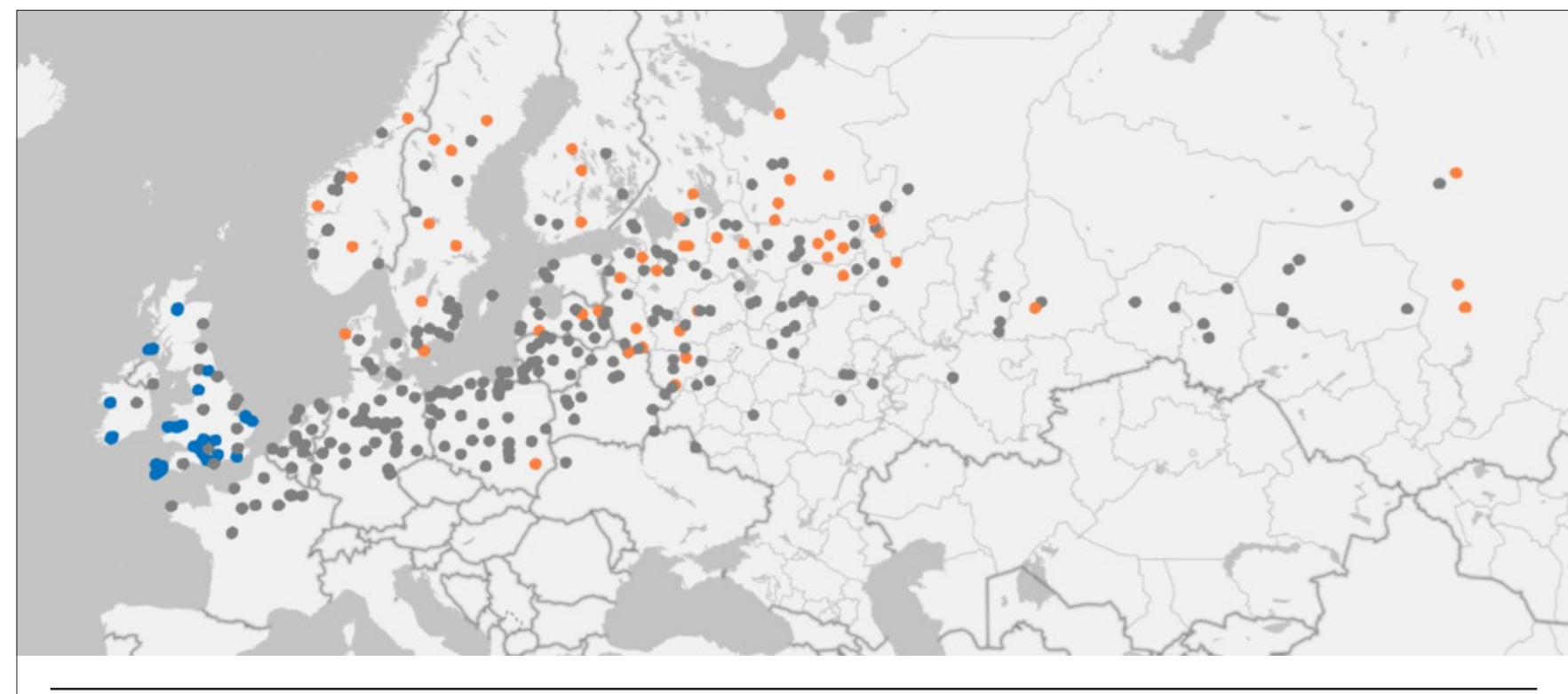

Figure 3. Map showing winter (blue), stopover (gray), and breeding (orange) sites of all tracked European woodcock that completed a spring migration. For individuals tracked in $>1$ year, only the locations during the first spring in which that individual was tracked are shown. 
only transmit for 10 hours in every 58 hours to conserve power. This inevitably means that some information concerning an individual's trajectory and timing of movements is missed. This is compounded by the fact that the tags do not always charge sufficiently to transmit during every duty cycle, especially in fall and winter, which means that satellite tags provide incomplete data. Further work using GPS tags, delivering more accurate and frequent locations, seems to be the way forward to complete our understanding of Eurasian woodcock flyways and fall migrations. Ideally, this should involve collaboration between researchers in different parts of the European wintering range, along with the tagging of individuals on breeding grounds.

\section{Management Implications}

Our study provides some of the first data for informing hunting policies on Eurasian woodcock and identifies potential issues for which further data collection would be valuable. Accurate arrival dates in Britain were obtained only for a very small number of individuals, but all were in November. This has implications for hunting management, as the European woodcock shooting season in Scotland opens on 1 September and in England, Wales, and Ireland on 1 October. The majority of Eurasian woodcock shot before November are, therefore, highly likely to be resident breeders. There is currently concern about a longterm decline in the British breeding Eurasian woodcock population (Heward et al. 2015), the reasons for which are currently unclear. Hence, hunters could reduce shooting mortality on this population by refraining from shooting Eurasian woodcock before November. The high fidelity of migrant Eurasian woodcock to particular wintering sites is also important: high shooting pressure in localized areas will likely impact adult Eurasian woodcock and break the migratory links with these sites.

Eurasian woodcock hunting is permitted in most European countries with the exception of Slovenia, parts of Switzerland, the Netherlands, and the Flanders region of Belgium (Ferrand and Gossmann 2009a). Along with harvesting in Britain and Ireland, Eurasian woodcock following most migration routes will also be susceptible to shooting at stopover sites during fall. A better understanding of this cumulative pressure along different migration routes is clearly an important step towards ensuring sustainable flyway management. Relative to the annual bag in the UK, estimated at 160,000 (PACEC 2014), bags taken mainly during periods of passage through the Baltic States, Finland, Scandinavia, and Germany between October and December are small (1,300-6,00o per country, Lutz and Jensen 2005). However, our study highlights the importance of northern Germany, Denmark, and southern Sweden as a passage area for Eurasian woodcock travelling between Finland, Sweden, and the British Isles. The Eur- asian woodcock season in Denmark runs from 1 October to 31 December, and the annual bag estimate $(25,000)$ is relatively high compared to that of neighbouring countries (Lutz and Jensen 2005). Little information is available concerning European woodcock bags in Poland and Belarus, and more accurate determinations for these countries are desirable. An attempt to quantify the relative impact of hunting on Eurasian woodcock originating from different breeding zones would be valuable, but the fundamental issue is whether the bags, in aggregate, are affecting the number of breeding Eurasian woodcock in Europe. Monitoring data from Scandinavia and Russia suggest that numbers there are currently stable (Fokin and Blokhin 2013, Lindström et al. 2015).

\section{Acknowledgments}

We are grateful to all the landowners who offered up sites for the study, to Owen Williams, Tony Cross and Luke Harman for help with deploying tags in Wales and Ireland, and to David Pepper, Sebastian Aebischer, and James Long for assistance with database management. We thank Nicholas Aebischer, Thomas Cooper, and 2 anonymous referees for constructive comments on the manuscript. The study was funded by the Shooting Times Woodcock Club and many private donors.

\section{Literature Cited}

Aebischer, A., N. Perrin, M. Krieg, J. Studer, and D.R. Meyer. 1996. The role of territory choice, mate choice and arrival date on breeding success in the Savi's warbler Locustella luscinioides. Journal of Avian Biology 27:134-152.

Argos. 2016. Argos User's Manual. http://www.argos-system.org/ manual/. Accessed o6 October 2017.

Arizaga, J., A. Crespo, I. Telletxea, R. Ibáñez, F. Díez, J.F. Tobar, M. Minondo, Z. Ibarrola, J.J. Fuente, and J.A. Pérez. 2014. Solar/ Argos PTTs contradict ring-recovery analyses: woodcocks wintering in Spain are found to breed further east than previously stated. Journal of Ornithology 156:515-523.

Bauthian, I., F. Gossmann, Y. Ferrand, and R. Julliard. 2007. Quantifying the origin of woodcock wintering in France. Journal of Wildlife Management 71:701-705.

BirdLife International. 2015. European Red List of Birds. Office for Official Publications of the European Communities, Luxembourg.

Bouten, W., E.W. Baaij, J. Shamoun-Baranes, and K.C.J. Camphuysen. 2013. A flexible GPS tracking system for studying bird behaviour at multiple scales. Journal of Ornithology 154:571-58o.

Britten, M.W., P.L. Kennedy, and S. Ambrose. 1999. Performance and accuracy evaluation of small satellite transmitters. Journal of Wildlife Management 63:1349-1358.

Burton, N.H.K. 200o. Winter site-fidelity and survival of redshank Tringa totanus at Cardiff, south Wales. Bird Study 47:102-112.

Burton, N.H.K., and P.R. Evans. 1997. Survival and winter site-fidelity of turnstones Arenaria interpres and purple sandpipers Calidris maritima in north-east England. Bird Study 44:35-44.

Currie, D., D.B.A. Thompson, and T. Burke. 2000. Patterns of territory settlement and consequences for breeding success in the wheatear Oenanthe oenanthe. Ibis 142:389-398. 
Estoppey, F. 2001. Le déclin de la population de bécasse des bois Scolopax rusticola du Jorat (Vaud, Suisse). Nos Oiseaux 48:83-92.

Egevang, C., I.J. Stenhouse, R.A. Phillips, A. Petersen, J.W. Fox, and J.R.D. Silk. 2010. Tracking of Arctic terns Sterna paradisaea reveals longest animal migration. Proceedings of the National Academy of Science 107:2078-2081.

Ferrand, Y., and F. Gossmann. 2009a. La Bécasse des Bois. Histoire naturelle. Effet de lisière, Saint-Lucien.

Ferrand, Y., and F. Gossmann. 2009b. Part 5: Ageing and sexing the Eurasian woodcock Scolopax rusticola. Wader Study Group Bulletin 116:75-79.

Fokin, S., and Y. Blokhin. 2013. Monitoring of the woodcock population in European Russia (1996-2010). Pages 29-35 in Y. Ferrand, ed. Seventh European Woodcock and Snipe Workshop. Office national de la chasse et de la faune sauvage, Paris, France.

Gonçalves, D. and T.M. Rodrigues. 2017. FANBPO Annual Report on Woodcock (FAROW) - 2015-2016 hunting season. Federation of Western Palearctic National Woodcock Hunters Associations (FANBPO), 43 pp. http://www.fanbpo.fr/uploaded/farow-report-bilingue-final-2017.pdf

Guilford, T.C., J. Meade, R. Freeman, D. Biro, T. Evans, F. Bonadonna, D. Boyle, S. Roberts, and C.M. Perrins. 2008. GPS tracking of the foraging movements of manx shearwaters Puffinus puffinus breeding on Skomer Island, Wales. Ibis 150:462-473.

Guzmán, J.L., J. Caro, and B. Arroyo. 2017. Factors influencing mobility and survival of Eurasian woodcock wintering in Spain. Avian Conservation \& Ecology 12:21.

Guzmán, J.L., Y. Ferrand, and B. Arroyo. 2011. Origin and migration of woodcock Scolopax rusticola wintering in Spain. European Journal of Wildlife Research 57:647-655.

Hasselquist, D. 1998. Polygyny in great reed warblers: a longterm study of factors contributing to male fitness. Ecology 79:2376-2390.

Hays, G.C., S. Åkesson, B.J. Godley, P. Luschi, and P. Santidrian. 2001. The implications of location accuracy for the interpretation of satellite-tracking data, Animal Behaviour 61:1035-1040.

Hewson, C.M., K. Thorup, J.W. Pearce-Higgins, and P.W. Atkinson. 2016. Population decline is linked to migration route in the common cuckoo. Nature Communications 7:12296.

Heward, C.J., A.N. Hoodless, G.J. Conway, N.J. Aebischer, S. Gillings, and R.J. Fuller. 2015. Current status and recent trend of the Eurasian woodcock Scolopax rusticola as a breeding bird in Britain. Bird Study 62:535-551.

Hill, R. 1994. Theory of geolocation by light levels. Pages 227-236 in B. LeBeouf and R. Laws, eds. Elephant seals: population ecology, behaviour and physiology. University of California Press, Berkeley, California, USA.

Hobson, K.A., S.L. Van Wilgenburg, J.L. Guzmán, and B. Arroyo. 2013a. Origins of juvenile woodcock (Scolopax rusticola) harvested in Spain inferred from stable hydrogen isotope $\left(\delta_{2} \mathrm{H}\right)$ analyses of feathers. Journal of Ornithology 154:1087-1094.

Hobson, K.A., S.L. Van Wilgenburg, Y. Ferrand, F. Gossmann, and C. Bastat. $2013 \mathrm{~b}$. A stable isotope approach $\left(\delta_{2} \mathrm{H}\right)$ to deriving origins of harvested woodcock (Scolopax rusticola) taken in France. European Journal of Wildlife Research 59:881-892.

Hoodless, A.N., and J.C. Coulson. 1994. Survival rates and movements of British and Continental woodcock Scolopax rusticola in the British Isles. Bird Study 41:48--6o.

Hoodless, A.N., A. Powell, Y. Ferrand, A. Gosler, J. Fox, J. Newton, and O. Williams. 2013. Application of new technologies to the study of Eurasian woodcock migration. Pages 7-18 in Y. Ferrand, ed. Seventh European Woodcock and Snipe Workshop. Office national de la chasse et de la faune sauvage, Paris, France.

Kokko, H. 1999. Competition for early arrival in migratory birds. Journal of Animal Ecology 68:940-950.
Klaassen, R.H. G, T. Alerstam, P. Carlsson, J.W. Fox, and Å. Lindström. 2011. Great flights by great snipes: long and fast non-stop migration over benign habitats. Biology Letters 7:833-835.

Lindström, Å., M. Green, M. Husby, J.A. Kålås, and A. Lehikoinen. 2015. Large-scale monitoring of waders on their boreal and Arctic breeding grounds in northern Europe. Ardea 103:3-15.

Lopez, R. and J.P. Malardé. 2011. Improving ARGOS doppler location using Kalman filtering. Argos System technical paper http://www.argos-system.org/wp-content/uploads/2016/o7/ r282_9_technical_paper.pdf

Lourenço, P.M., J.A. Alves, J. Reneerkens, A.H.J. Loonstra, P.M. Potts, J.P. Granadeiro, and T. Catry. 2016. Influence of age and sex on winter site fidelity of sanderlings Calidris alba. PeerJ 4:e2517.

Lozano, G.A., S. Perreault, and R.E. Lemon. 1996. Age, arrival date and reproductive success of male American redstarts Setophaga ruticilla. Journal of Avian Biology 27:164-170.

Lutz, M., and F.P. Jensen. 2005. European Union Management Plan for Woodcock Scolopax rusticola 2006-2009. European Commission, Brussels, Belgium.

Marcström, V., and J.W. Mascher. 1979. Weights and fat in lapwings Vanellus vanellus and oystercatcher Haematopus ostralegus starved to death during a cold spell in spring. Ornis Scandinavica 10:235-240.

Marra, P.P., K.A. Hobson, and R.T. Holmes. 1998. Linking winter and summer events in a migratory bird using stable carbon isotopes. Science 282:1884-1886.

Marra, P.P., C.M. Francis, R.S. Mulvihill, and F.R. Moore. 2005. The influence of climate on the timing and rate of spring bird migration. Oecologia 142:307-315.

McKelvie, C.L. 1990. The nook of the woodcock. 2nd Edition. Swan Hill Press, Shrewsbury, England.

Møller, A.P., and K.A. Hobson. 2003. Heterogeneity in stable isotope profiles predicts coexistence of two populations of barn swallows Hirundo rustica differing in morphology and reproductive performance. Proceedings of the Royal Society, London B 271:1355-1362.

Mulhauser, B. 2001. Situation de la bécasse des bois Scolopax rusticola en période de reproduction dans le canton de Neuchâtel (Suisse) entre 1998 et 2000. Nos Oiseaux 48:93-104.

Niles, L.J., J. Burger, R.R. Porter, A.D. Dey, C.D.T. Minton, P.M. Gonzalez, A.J. Baker, J.W. Fox, and C. Gordon. 2010. First results using light level geolocators to track red knots in the Western Hemisphere show rapid and long intercontinental flights and new details of migration pathways. Wader Study Group Bulletin 117:123-130.

Norris, D.R., P.P. Marra, T.K. Kyser, T.W. Sherry, and L.M. Ratcliffe. 2003. Tropical winter habitat limits reproductive success on the temperate breeding grounds in a migratory bird. Proceedings of the Royal Society, London B 271:59-64.

PACEC. 2014. The value of shooting. The economic, environmental, and social benefits of shooting sports in the UK. PACEC, Cambridge, UK.

Péron, G., Y. Ferrand, F. Gossmann, C. Bastat, M. Guenezan, and O. Gimenez. 2011. Nonparametric spatial regression of survival probability: visualization of population sinks in Eurasian woodcock. Ecology 92:1672-1679.

Péron, G., Y. Ferrand, R. Choquet, R. Pradel, F. Gossmann, C. Bastat, M. Guézénan, I. Bauthian, R. Julliard, and O. Gimenez. 2012. Spatial heterogeneity in mortality and its impact on the population dynamics of Eurasian woodcocks. Population Ecology 54:305-312.

Rappole, J.H., and A.R. Tipton. 1991. New harness design for attachment of radio transmitters to small passerines. Journal of Field Ornithology 62:335-337.

Smith, K.W., J.M. Reed, and B.E. Trevis. 1992. Habitat use and site fidelity of green sandpipers Tringa ochropus wintering in Southern England. Bird Study 39:155-164. 
Sokolov, L.V. 2001. Climate influence on year-to-year variations in timing of migration and breeding phenology in passerines on the Cournish Spit. The Ring 231:159-166.

Stutchbury, B.J.M., S.A. Tarof, T. Done, E. Gow, P.M. Kramer, J. Tautin, J.W. Fox, and V. Afanasyev. 2009. Tracking long-distance songbird migration by using geolocators. Science 323:896.

Tavecchia, G., R. Pradel, F. Gossman, C. Bastat, Y. Ferrand, and J.D. Lebreton. 2002. Temporal variation in annual survival probability of the Eurasian woodcock Scolopax rusticola wintering in France. Wildlife Biology 8:21-30.

Tryjanowski, P., T.H. Sparks, J. Ptaszyk, and J. Kosicki. 2004. Do white storks Ciconia ciconia always profit from an early return to their breeding grounds? Bird Study 51:222-227.

Van Wilgenburg, S., and K. Hobson. 2011. Combining stable isotope $(\delta \mathrm{D})$ and band recovery data to improve probabilistic assign- ment of migratory birds to origin. Ecological Applications 21:1340-1351.

Webster, M.S., P.P. Marra, S.M. Haig, S. Bensch, and R.T. Holmes. 2002. Links between worlds: unravelling migratory connectivity. Trends in Ecology and Evolution 17:76-83.

Wernham, C.V., M.P. Toms, J.H. Marchant, J.A. Clark, G.M. Siriwardena, and S.R. Baillie. 2002. The migration atlas: movements of the birds of Britain and Ireland. Poyser, London, UK.

Whitmore, R.C., J.A. Mosher, and H.H. Frost. 1977. Spring migrant mortality during unseasonable weather. Auk 94:778-781.

Wilson, J. 1983. Wintering site fidelity of woodcock in Ireland. Pages 18-27 in H. Kalchreuter, ed. Proceedings of the Second European Woodcock \& Snipe Workshop. International Waterfowl Research Bureau, Slimbridge, UK. 